\title{
Transtrochanteric approach can provide better postoperative care and lower complication rate in the treatment of hip fractures
}

This article was published in the following Dove Medical Press journal: Clinical Interventions in Aging

\author{
Safa Gursoy' \\ Mehmet Emin Simsek ${ }^{2}$ \\ Mustafa Akkaya' \\ Metin Dogan' \\ Murat Bozkurt' \\ 'Department of Orthopedics and \\ Traumatology, Ankara Yildirim Beyazit \\ University, Ankara 06800, Turkey; \\ ${ }^{2}$ Department of Orthopedics and \\ Traumatology, Yenimahalle Training \\ and Research Hospital, Ankara 06370, \\ Turkey
}

Purpose: Dislocation is an important complication that increases the mortality, morbidity, and postoperative care following bipolar hemiarthroplasty. It is thought that the transtrochanteric approach that enables access to the femoral neck directly from the fracture line at the coronal plane of the greater trochanter without opening the posterior and anterior capsules could reduce the risk of dislocation. Additionally, it is argued that preservation of the external rotators could also be advantageous for patient rehabilitation and muscle strength. The aim of this study is to compare the effectiveness of the standard posterolateral approach and transtrochanteric approach performed from the fracture line, primarily the rate of dislocation, in osteoporotic Evans Type IV-V unstable intertrochanteric fractures on which bipolar hemiarthroplasty was performed. Patients and method: One hundred and twelve patients had Type IV-V fracture according to Evans classification and underwent hemiarthroplasty were enrolled in the study. Patients operated using the posterolateral approach, that is, Group $1(n=48)$, and patients operated using the transtrochanteric (transfracture) approach, that is, Group $2(n=64)$, were compared in terms of dislocation, surgical duration, amount of blood transfusion, infection, mortality, and trochanteric nonunion. Factors that could affect the development of dislocation from the patient, surgery, and implant were also analyzed.

Results: It was found that the rate of dislocation was statistically significantly higher in Group 1 in comparison to Group $2(P<0.05)$. It was also observed that the surgical duration was statistically significantly shorter in Group $2(P<0.05)$. It was found that the presence of a cognitive disorder, trochanteric nonunion, and use of posterolateral surgical approach resulted in a statistically significant increase in the rate of dislocation $(P<0.05)$.

Conclusion: Transtrochanteric (transfracture) approach is an effective method for minimizing possible complications following hemiarthroplasty, especially dislocation.

Keywords: hip fractures, bipolar hemiarthroplasty, elderly, dislocation

\section{Introduction}

Pertrochanteric fracture is an important entity that causes high mortality and morbidity, with the 1-year mortality rate being $30 \%$ in elderly individuals. ${ }^{1-3}$ These fractures constitute $45 \%$ of all hip fractures. ${ }^{1,4}$

Although the accepted primary treatment for stable hip fractures is osteosynthesis, one-third of the fractures in this region are constituted by unstable fractures. ${ }^{1,5}$ Internal fixation methods are associated with high complication rates in the elderly patient population, especially in case of unstable fractures. ${ }^{6-8}$ The observed complications and long-term bed rest that may be necessary following internal fixation further increase the risk of deep vein thrombosis, which is already high, and the complications
Correspondence: Safa Gursoy Department of Orthopedics and Traumatology, Ankara Yildirim Beyazit University, Ankara 06800, Turkey Tel +905054896632

Fax +903125872526

Email safagursoy@yahoo.com
Clinical Interventions in Aging 2019:14 |37-|43

137 
associated with it. ${ }^{9}$ In the light of this information, bipolar hemiarthroplasty can be the preferred primary treatment option for osteoporotic unstable hip fractures (Evans Types IV and V) in elderly patients.

One of the most common complications that increase mortality following bipolar hemiarthroplasty in elderly patients is dislocation. ${ }^{10}$ Various studies have reported dislocation rates ranging from $1 \%$ to $22 \%{ }^{11}$ It is asserted in many studies that the rate of dislocation is associated with the employed surgical approach. It is argued that the rate of dislocation is higher in the classical posterolateral approach in which the posterior capsule and external rotators are incised at the hip joint that tends to exhibit posterior dislocation. It was also demonstrated that the dislocation risk could be decreased by repairing posterior structures. ${ }^{12,13}$

In 2008, Bombaci defined the transtrochanteric approach that enables access to the femoral neck directly from the fracture line at the coronal plane of the greater trochanter without opening the posterior and anterior capsules. ${ }^{14}$ In this approach, the operation is distant from the sciatic nerve, which is at risk in the posterior approach, and it is thought that the risk of dislocation could be theoretically reduced as the capsules and external rotators are preserved as compared to the classical posterior approach. Additionally, it is argued that preservation of the external rotators could also provide advantage for patient rehabilitation and muscle strength. However, there are no comparative studies on this subject in the literature.

In this study, our aim was to compare the effectiveness of the standard posterolateral approach with that of the transtrochanteric approach performed from the fracture line, and primarily the rate of dislocation, in osteoporotic Evans Type IV-V unstable intertrochanteric fractures on which bipolar hemiarthroplasty was performed.

\section{Patients and methods}

This retrospective comparative study was approved by the Institutional Review Board (IRB) of our hospital (Yenimahalle Hospital IRB no: 2018/60). Since the study was retrospective, informed consent by patients and providers was not required. The collection of medical records complies with patient data confidentiality and the Declaration of Helsinki. Two hundred sixty-four hip fractures operated between 2014 and 2017 at our clinic were retrospectively screened in this study. Among these fractures, 112 patients who had Type IV-V fractures according to Evans classification and underwent hemiarthroplasty were enrolled in the study. Patients operated in our clinic using the classical posterolateral approach before June 2015 constituted Group $1(n=48)$, and those operated in our clinic using the transtrochanteric (transfracture) approach that was included in practice after June 2015 constituted Group 2 ( $n=64)$. All surgeries were performed by two surgeons with equal experience and seniority. Among the patients included in the study, 72 were implanted using cemented bipolar hemiarthroplasty purchased from Bi-Metric stem (Biomet, Sylvania, OH, USA), whereas 40 patients were implanted using uncemented modular bipolar hemiarthroplasty after evaluation according to patients' cortical index (T2 Hip Prosthesis; Tipsan, Bornova/İzmir, Turkey). Mean age of the patients in groups 1 and 2 was $86.5 \pm 6.5$ and $87.1 \pm 5.7$ years, respectively. Thirty-one $(64.6 \%)$ patients in Group 1 and 47 (73.4\%) patients in Group 2 were female. Demographic characteristics and morbidities of patients, such as body mass index, status according to American Society of Anesthesiologists (ASA) classification, and presence of a cognitive disorder diagnosed by a neurologist at preoperative evaluation or obtained from patient records, as well as the distribution thereof by groups are provided in Table 1.

Patient records of the subjects who participated in the study were reviewed, and postoperative amount of blood transfusion, surgical duration, early mortalities, and time from admission to the hospital until surgery were recorded. Patient follow-up records were reviewed in order to investigate and analyze the complications such as mortality, infection, and dislocation for comparison between the two groups. Rate of dislocation was compared between the two groups, in addition to the analysis of factors such as bipolar head size that could affect dislocation.

Patients who were given an ASA score of 4 by the anesthesiology clinic, patients with pathologic fractures or multiple trauma, patients diagnosed with advanced Alzheimer's disease, patients with inadequate outpatient follow-up, noncompliant patients, and patients with noncompliant relatives were not included in any group of this study.

\section{Surgical technique \\ Posterolateral approach}

Patients included in Group 1 were placed in the lateral decubitus position. Following a posterolateral skin incision and moving past the tensor fascia lata, the gluteus maximus was split along its proximal fibers. Then, the external rotators were separated at the point of attachment to the trochanter moving along the posterior aspect of the joint and a T-shaped incision was made on the capsule in order to excise the fractured femoral head. Following femur preparation in internal rotation, femoral stem was placed cemented or uncemented 
Table I Distribution of the demographic and clinical characteristics of the patients included in the study by groups and statistical analysis of the differences between the two groups

\begin{tabular}{|c|c|c|c|}
\hline & Posterolateral (Group I) & Transtrochanteric (Group 2) & \multirow[t]{2}{*}{$P$-value } \\
\hline & n (\%) & n (\%) & \\
\hline \multicolumn{4}{|l|}{ Gender } \\
\hline Female & $31(64.6)$ & $47(73.4)$ & \multirow[t]{2}{*}{0.407} \\
\hline Male & $17(35.4)$ & $17(26.6)$ & \\
\hline Age, years (mean $\pm S D$ ) & $86.5 \pm 6.5$ & $87.1 \pm 5.7$ & 0.602 \\
\hline $\mathrm{BMI}, \mathrm{kg} / \mathrm{m}^{2}($ mean $\pm \mathrm{SD})$ & $27.2 \pm 3.9$ & $26.4 \pm 4.2$ & 0.325 \\
\hline Follow-up, months (mean $\pm S D$ ) & $50.5 \pm 4.1$ & $37.1 \pm 5.1$ & $0.000 \mathrm{I}$ \\
\hline \multicolumn{4}{|l|}{ Cognitive disorder } \\
\hline No & $37(77.1)$ & $5 \mathrm{I}(79.7)$ & \multirow[t]{2}{*}{0.818} \\
\hline Yes & II (22.9) & I3 (20.3) & \\
\hline \multicolumn{4}{|l|}{ ASA } \\
\hline 1 & $6(12.5)$ & $9(14.1)$ & \multirow[t]{3}{*}{0.571} \\
\hline 2 & $14(29.2)$ & $24(37.5)$ & \\
\hline 3 & $28(58.3)$ & $31(48.4)$ & \\
\hline \multicolumn{4}{|l|}{ Prosthesis } \\
\hline Bi-Metric (cemented fixation) & $34(70.8)$ & $38(59.4)$ & \multirow[t]{2}{*}{0.237} \\
\hline T2 (uncemented fixation) & $14(29.2)$ & $26(40.6)$ & \\
\hline Head size & $47.9 \pm 3.2$ & $47.1 \pm 3.2$ & 0.170 \\
\hline
\end{tabular}

Abbreviation: ASA, American Society of Anesthesiologists classification.

Note: Bold values indicate statistical significance $P<0.05$.

depending on the technique. Fixation of the fractured fragment in the greater trochanter was performed using trochanteric grip and cable. External rotators and capsule were sutured back to the trochanter and repaired.

\section{Transtrochanteric (transfracture) approach}

Patients included in Group 2 were subjected to the same stages with a posterolateral skin incision. Then, the fracture line at the coronal plane of the trochanter was split in order to expose the femoral neck without moving past the external rotators and capsule (Figures 1 and 2). The femoral head was

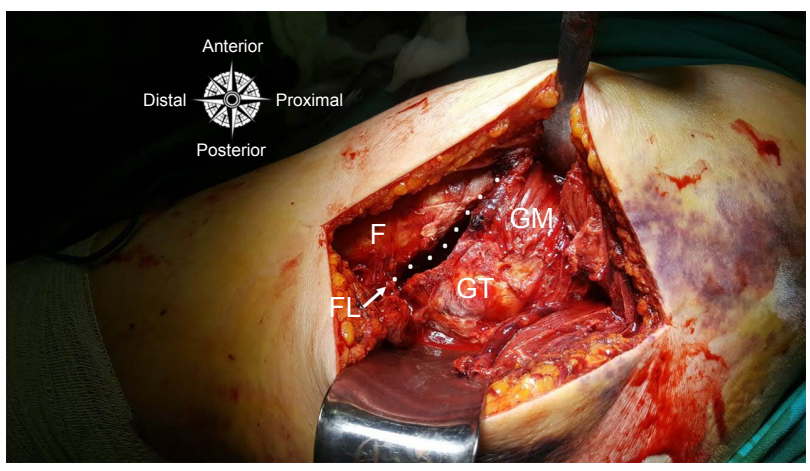

Figure I Transtrochanteric approach surgical technique.

Note: Accessing the femoral neck from the fracture line on the proximal femur indicated by dots.

Abbreviations: F, femur; FL, fracture line; GM, gluteus medius; GT, greater trochanter. excised with a superior incision of $1-2 \mathrm{~cm}$. The same method was used for femoral stem implantation and fixation of the trochanter fracture.

\section{Statistical analysis}

SPSS 17.0 software package was used for the statistical analysis of data. Categorical measurements were given as numbers and percentage values, whereas continuous measurements were given as mean and SD values (median and minimum-maximum when necessary). Chi-squared test or Fisher's test was used for comparing the categorical

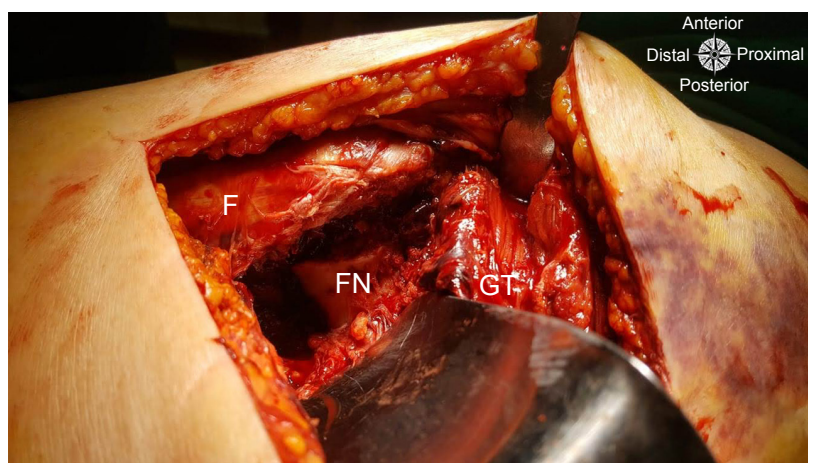

Figure 2 Transtrochanteric approach surgical technique.

Note: Discarding the proximal part after accessing through the fracture line and reaching the femoral neck.

Abbreviations: F, femur; FN, femoral neck; GT, greater trochanter. 
variables. Distributions were analyzed on comparing continuous variables between the groups, wherein Student's $t$-test was used for variables that had a parametric distribution and Mann-Whitney $U$ test for variables that did not have a parametric distribution. Independent risk factors that affect the formation of dislocation were determined using logistic regression analysis. Statistical significance level was accepted as 0.05 for all tests.

\section{Results}

According to the statistical comparison of the groups, it was found that the rate of dislocation was statistically significantly higher in Group 1 compared to Group $2(P<0.05)$. Comparison of all the studied parameters is provided in detail in Table 2. Comparison of the patients in groups 1 and 2 in terms of demographic and clinical characteristics revealed that the only nonhomogenous distribution resulted in a statistical difference $(P<0.05)$ in terms of the follow-up period (from the date of surgery to the date of collection of data for the study), as shown in Table 1.

Analysis of other factors that could affect the formation of dislocation is provided in Table 3. It was found that the presence of a cognitive disorder, trochanteric nonunion, and use of posterolateral surgical approach resulted in a statistically significant increase in the rate of dislocation $(P<0.05)$. No statistically significant difference was found related to fixation method (Bi-Metric cemented prosthesis vs T2 uncemented prosthesis) in terms of dislocation rate $(P=0.743)$. Independent risk factors that could affect the formation of dislocation were investigated using logistic regression analysis (Table 4). Parameters that showed significant results in the univariate analysis were added to the model. Independent risk factors that affect the formation of dislocation in a patient were identified. It was found that the presence of a cognitive disorder, trochanteric nonunion, and use of posterolateral surgical approach increased the risk of developing dislocation in a patient $(P<0.05)$.

\section{Discussion}

This study has shown that the transtrochanteric approach that could be performed from the fracture line at the trochanter without incision of the external rotators and capsule in osteoporotic Evans IV-V fractures in elderly patients was more effective in preventing dislocation, which is an important problem that increases morbidity in bipolar hemiarthroplasty, in comparison to the standard posterior approach. Analysis concerning incidence of dislocations revealed that the difference between the two groups was statistically significant $(P<0.05)$.

This approach enables reducing the risk of dislocation as well as decreasing the amount of bleeding since external rotators and capsule are not incised. Although the mean amount of blood transfusion for patients in Group 2 after the operation was lower in comparison to the standard posterolateral approach, the difference between the two approaches was not statistically significant. Moreover, the surgery is performed at a distance from the sciatic nerve, which is under risk in the posterior approach. Another potential advantage of this approach is that concerning nonunion, which is a significant problem in the fixation of the trochanter; a better union can be provided without disrupting the vascular support of the

Table 2 Comparison of the two surgical techniques

\begin{tabular}{|c|c|c|c|c|}
\hline Parameter & $\begin{array}{l}\text { Posterolateral } \\
\text { (Group I, n=48) }\end{array}$ & $\begin{array}{l}\text { Transtrochanteric } \\
\text { (Group 2, n=64) }\end{array}$ & Total & $P$-value \\
\hline Surgical duration, minutes & $66.6 \pm 10.4$ & $60.0 \pm 10.5$ & $62.9 \pm 10.9$ & 0.001 \\
\hline Amount of blood replacement (units of RBCs) & $2(2-5)$ & I (0-4) & I (0-5) & 0.175 \\
\hline $\begin{array}{l}\text { Dislocation, n (\%) } \\
\text { Yes } \\
\text { No }\end{array}$ & $\begin{array}{l}8(16.7) \\
40(83.3)\end{array}$ & $\begin{array}{l}3(4.7) \\
61(95.3)\end{array}$ & $\begin{array}{l}\text { II (I0.7) } \\
\text { I0I (89.3) }\end{array}$ & 0.035 \\
\hline $\begin{array}{l}\text { Deep infection, } n(\%) \\
\text { Yes } \\
\text { No }\end{array}$ & $\begin{array}{l}2(4.2) \\
46(95.8)\end{array}$ & $\begin{array}{l}2(3.1) \\
62(96.9)\end{array}$ & $\begin{array}{l}4(3.6) \\
108(96.4)\end{array}$ & 1.000 \\
\hline $\begin{array}{l}\text { Mortality in } 90 \text { days, } n(\%) \\
\text { Yes } \\
\text { No }\end{array}$ & $\begin{array}{l}\text { I4 (29.2) } \\
34(70.8)\end{array}$ & $\begin{array}{l}13(20.3) \\
51(79.7)\end{array}$ & $\begin{array}{l}27(24.1) \\
85(75.9)\end{array}$ & 0.372 \\
\hline $\begin{array}{l}\text { Trochanteric nonunion, } \mathrm{n}(\%) \\
\text { Yes } \\
\text { No }\end{array}$ & $\begin{array}{l}10(20.9) \\
38(79.1)\end{array}$ & $\begin{array}{l}9(14.1) \\
55(85.9)\end{array}$ & $\begin{array}{l}19(16.9) \\
93(83.1)\end{array}$ & 0.447 \\
\hline
\end{tabular}

Notes: According to the analysis, there was a statistically significant difference in terms of dislocation and surgical duration. Bold values indicate statistical significance $P<0.05$. Abbreviations: RBCs, red blood cells. 
Table 3 Analysis of other factors that affect the formation of dislocation

\begin{tabular}{|c|c|c|c|}
\hline & Dislocation no $(n=101)$ & Dislocation yes $(n=I I)$ & $P$-value \\
\hline Age, years & $86.9 \pm 5.9$ & $85.9 \pm 7.4$ & 0.592 \\
\hline BMI, kg/m² & $26.6 \pm 4.1$ & $27.6 \pm 3.9$ & 0.428 \\
\hline Head size, mm & $47.4 \pm 3.2$ & $47.4 \pm 3.8$ & 0.978 \\
\hline Time period until surgery, days & $4(1-10)$ & $3(2-8)$ & 0.320 \\
\hline \multicolumn{4}{|l|}{ Gender } \\
\hline Female & $71(70.3)$ & $7(63.6)$ & \multirow[t]{2}{*}{0.733} \\
\hline Male & $30(29.7)$ & $4(36.4)$ & \\
\hline Cognitive disorder (yes) & $16(15.8)$ & $8(72.7)$ & 0.0001 \\
\hline Trochanteric nonunion (yes) & II (I0.9) & $8(72.7)$ & 0.0001 \\
\hline \multicolumn{4}{|l|}{ Surgical approach } \\
\hline Posterolateral & $40(36.9)$ & $8(72.7)$ & \multirow[t]{2}{*}{0.035} \\
\hline Transtrochanteric & $61(60.4)$ & $3(27.3)$ & \\
\hline \multicolumn{4}{|l|}{ Prosthesis type } \\
\hline Bi-Metric (cemented fixation) & $64(63.4)$ & $8(72.7)$ & \multirow[t]{2}{*}{0.743} \\
\hline T2 (uncemented fixation) & $37(36.6)$ & $3(27.3)$ & \\
\hline
\end{tabular}

Notes: It is seen from the table that the presence of a cognitive disorder, trochanteric nonunion, and use of posterolateral surgical approach result in a statistically significant increase in the rate of dislocation. Bold values indicate statistical significance $P<0.05$.

fragment since posterior vascular structures are preserved. It is thought that preservation of the external rotators could also be advantageous for patient rehabilitation and muscle strength.

According to the literature, apart from the surgical approach, there are many factors (time to surgery, gender, mental status of the patient, fixation method, etc) that have an impact on the risk of dislocation following bipolar hemiarthroplasty. ${ }^{15-23}$ The relationship between fixation method, bipolar head size, mental status of the patients, gender, time until surgery, and dislocation was also analyzed irrespective of the surgical approach. Many studies have reported that there is no difference between the fixation methods (cemented vs uncemented) in terms of dislocation. ${ }^{16-18}$ The results of this study were similar to the data in the literature in that there was no statistically significant difference between cemented and uncemented fixation in terms of dislocation $(P=0.743)$. It is argued that using larger femoral head significantly reduces the risk of dislocation in total hip arthroplasty. ${ }^{19}$ Although theoretically a lower rate of dislocation is expected as the "jumping distance" would increase when using large bipolar heads, the number of comparative studies on this subject is very limited. However, it is asserted that the use of smaller heads as a result of a faulty measurement of the excised head size could be associated with early acetabular degradation and protrusion. In our study, there was no statistically significant difference in terms of the head size used in patients who experienced and did not experience dislocation $(P=0.978)$. However, it would be more meaningful to evaluate these patients by measuring the excised head or conducting contralateral measurements. Madanat et $\mathrm{al}^{20}$ and Salem et $\mathrm{a}^{21}$ have shown in their studies that there was a direct correlation between time from admission to the hospital until surgery and dislocation. These studies reported that exceeding 24 and 48 hours could increase the risk of dislocation. In

Table 4 Logistic regression analysis

\begin{tabular}{|c|c|c|c|c|c|c|c|c|}
\hline & \multirow[t]{2}{*}{ B } & \multirow[t]{2}{*}{ SE } & \multirow[t]{2}{*}{ Wald } & \multirow[t]{2}{*}{$d f$} & \multirow[t]{2}{*}{$P$-value } & \multirow[t]{2}{*}{ OR } & \multicolumn{2}{|c|}{ 95\% $\mathrm{Cl}$ for $\mathrm{OR}$} \\
\hline & & & & & & & Lower & Upper \\
\hline Surgical approach (posterolateral) & 2.12 & 1.016 & 4.36 & 1 & 0.037 & 8.3 & 1.14 & 61.10 \\
\hline Cognitive disorder (yes) & 2.72 & 0.941 & 8.35 & 1 & 0.004 & 15.1 & 2.40 & 95.81 \\
\hline Trochanteric nonunion (yes) & 3.02 & 0.918 & 10.79 & 1 & 0.001 & 20.4 & 3.38 & 123.69 \\
\hline Constant & -5.88 & 1.384 & 18.02 & I & 0.0001 & 0.003 & & \\
\hline
\end{tabular}

Notes: The table shows that the presence of a cognitive disorder, trochanteric nonunion, and use of posterolateral surgical approach increase the risk of developing dislocation in a patient. Bold values indicate statistical significance $P<0.05$.

Abbreviation: SE, standard error. 
our study, there was no relationship between increase in this time period and the rate of dislocation $(P=0.320)$. However, it was understood that among the patients operated at our clinic, the number of those operated within 48 hours upon admission to the hospital was very low.

It was demonstrated that factors related to the patient, such as cognitive status and gender, had an effect on the rate of dislocation. In a study by Abram and Murray, it was found that the rate of dislocation was higher in females and patients with a cognitive disorder; however, the difference was not statistically significant. ${ }^{22}$ Ninh et al showed that there was a strong correlation between dislocation and the mental status of patients. ${ }^{23}$ The same study also revealed that male gender had a higher risk of dislocation. In our study, it was found that the rate of dislocation was statistically significantly higher in patients with a cognitive disorder $(P<0.05)$. The number of patients diagnosed with Parkinson's disease was not sufficient to conduct a statistical analysis. No difference was found in the statistical analysis in terms of gender $(P=0.733)$.

It is observed that dislocation generally develops within the first year, as indicated in the literature. However, the weakness of this study in terms of investigating long-term complications was that the mean follow-up periods were different between the two groups. Another weakness of this study was that measurement was not possible from the obtained radiographs to analyze the patient-related factors that could affect the development of dislocation, such as acetabular coverage and offset, and therefore it was not included in the study. Another limitation of this study is that the study design is retrospective. There is a need for prospective randomized comparative studies comparing hip approaches. The fact that it is the first study to compare quite a new approach that can be used in the prevention of dislocation, which is a significant problem in elderly individuals, with a standard approach and investigate the other factors that may affect dislocation can be considered as the strength of this study.

There are many studies investigating the effect of surgical approach on the rate of dislocation following hemiarthroplasty. According to an extensive meta-analysis and registry data, it is asserted that the rate of dislocation is higher in the posterior approach as compared to the anterolateral approach. $^{24,25}$ Transtrochanteric approach in primary total hip arthroplasty was first described by Charnley, ${ }^{26}$ followed by the description of Bombaci for the first time in hemiarthroplasty for intertrochanteric fractures involving access from the trochanteric fracture line. ${ }^{14}$ Limited case series have shown that successful outcomes could be achieved by using this new approach in fractures of the hip area. ${ }^{27,28}$ However, there are no comparative and detailed studies concerning this approach. This study has shown that the rate of dislocation in transtrochanteric approach performed from the fracture line was lower in comparison to the standard posterior approach, wherein factors that could affect the rate of dislocation were also analyzed.

\section{Conclusion}

The use of transtrochanteric (transfracture) surgical approach performed from the fracture line by preserving anterior and posterior structures in suitable patients is effective in minimizing possible complications following hemiarthroplasty, especially dislocation.

\section{Disclosure}

The authors report no conflicts of interest in this work.

\section{References}

1. Hassankhani EG, Omidi-Kashani F, Hajitaghi H, Hassankhani GG. How to treat the complex unstable intertrochanteric fractures in elderly patients? DHS or arthroplasty. Arch Bone Jt Surg. 2014;2(3):174-179.

2. Abrahamsen B, van Staa T, Ariely R, Olson M, Cooper C. Excess mortality following hip fracture: a systematic epidemiological review. Osteoporos Int. 2009;20(10):1633-1650.

3. Panula J, Pihlajamäki H, Mattila VM, et al. Mortality and cause of death in hip fracture patients aged 65 or older: a population-based study. $B M C$ Musculoskelet Disord. 2011;12(1):105.

4. Abdelkhalek M, Ali AM, Abdelwahab M. Cemented bipolar hemiarthroplasty with a cerclage cable technique for unstable intertrochanteric hip fractures in elderly patients. Eur J Orthop Surg Traumatol. 2013; 23(4):443-448

5. Grimsrud C, Monzon RJ, Richman J, Ries MD. Cemented hip arthroplasty with a novel cerclage cable technique for unstable intertrochanteric hip fractures. J Arthroplasty. 2005;20(3):337-343.

6. Mainds CC, Newman RJ. Implant failures in patients with proximal fractures of the femur treated with a sliding screw device. Injury. 1989;20(2):98-100.

7. Barrios C, Broström LA, Stark A, Walheim G. Healing complications after internal fixation of trochanteric hip fractures: the prognostic value of osteoporosis. J Orthop Trauma. 1993;7(5):438-442.

8. Sheikh IS. Intertrochanteric femur fracture in elderly treated with bipolar vs DHS - a prospective study. Journal of Medical Thesis. 2014; 2(Issue 2):45-49.

9. Rae PJ, Hodgkinson JP, Meadows TH, Davies DR, Hargadon EJ. Treatment of displaced subcapital fractures with the Charnley-Hastings hemiarthroplasty. J Bone Joint Surg Br. 1989;71-B(3):478-482.

10. Petersen MB, Jørgensen HL, Hansen K, Duus BR. Factors affecting postoperative mortality of patients with displaced femoral neck fracture. Injury. 2006;37(8):705-711.

11. Bhandari M, Devereaux PJ, Swiontkowski MF, et al. Internal fixation compared with arthroplasty for displaced fractures of the femoral neck. A meta-analysis. J Bone Joint Surg Am. 2003;85-A(9):1673-1681.

12. Ko CK, Law SW, Chiu KH. Enhanced soft tissue repair using locking loop stitch after posterior approach for hip hemiarthroplasty. $J$ Arthroplasty. 2001;16(2):207-211.

13. Macaulay W, Colacchio ND, Fink LA. Modified enhanced posterior soft tissue repair results in a negligible dislocation rate after hip resurfacing. Oper Tech Orthop. 2009;19(3):163-168. 
14. Bombaci $\mathrm{H}$. Transtrochanteric approach in intertrochanteric femur fractures. J Trauma. 2008;65(5):1171-1173.

15. Jones C, Briffa N, Jacob J, Hargrove R. The dislocated hip hemiarthroplasty: current concepts of etiological factors and management. Open Orthop J. 2017;11(Suppl-7, M4):1200-1212.

16. Langslet E, Frihagen F, Opland V, Madsen JE, Nordsletten L, Figved W. Cemented versus uncemented hemiarthroplasty for displaced femoral neck fractures: 5-year followup of a randomized trial. Clin Orthop Relat Res. 2014;472(4):1291-1299.

17. Deangelis JP, Ademi A, Staff I, Lewis CG. Cemented versus uncemented hemiarthroplasty for displaced femoral neck fractures: a prospective randomized trial with early follow-up. J Orthop Trauma. 2012;26(3):135-140.

18. Figved W, Opland V, Frihagen F, Jervidalo T, Madsen JE, Nordsletten L. Cemented versus uncemented hemiarthroplasty for displaced femoral neck fractures. Clin Orthop Relat Res. 2009;467(9):2426-2435.

19. Howie DW, Holubowycz OT, Middleton R; Large Articulation Study Group. Large femoral heads decrease the incidence of dislocation after total hip arthroplasty: a randomized controlled trial. J Bone Joint Surg Am. 2012;94(12):1095-1102.

20. Madanat R, Mäkinen TJ, Ovaska MT, Soiva M, Vahlberg T, Haapala J. Dislocation of hip hemiarthroplasty following posterolateral surgical approach: a nested case-control study. Int Orthop. 2012;36(5):935-940.
21. Salem KMI, Shannak OA, Scammell BE, Moran CG. Predictors and outcomes of treatment in hip hemiarthroplasty dislocation. Ann R Coll Surg Engl. 2014;96(6):446-451.

22. Abram SG, Murray JB. Outcomes of 807 Thompson hip hemiarthroplasty procedures and the effect of surgical approach on dislocation rates. Injury. 2015;46(6):1013-1017.

23. Ninh CC, Sethi A, Hatahet M, Les C, Morandi M, Vaidya R. Hip dislocation after modular unipolar hemiarthroplasty. J Arthroplasty. 2009;24(5):768-774.

24. Varley J, Parker MJ. Stability of hip hemiarthroplasties. Int Orthop. 2004;28(5):274-277.

25. Rogmark C, Fenstad AM, Leonardsson O, et al. Posterior approach and uncemented stems increases the risk of reoperation after hemiarthroplasties in elderly hip fracture patients. Acta Orthop. 2014;85(1):18-25.

26. Charnley J. Low Friction Arthroplasty of the Hip. Theory and Practice. Berlin, Heidelberg, New York: Springer; 1979.

27. Patil A. Role of cemented bipolar hemiarthroplasty for comminuted inter-trochanteric femur fracture in elderly osteoporotic patients through a modified transtrochanteric approach - "SION Hospital Modification". IOSR-JDMS. 2013;9(4):40-47.

28. Pradeep C, Anuj A, Abhishek G. Treatment of comminuted unstable inter-trochanteric fracture in elderly patients with cemented bipolar prosthesis. Indian J Orthop Surg. 2015;1(4):255-260.
Clinical Interventions in Aging

\section{Publish your work in this journal}

Clinical Interventions in Aging is an international, peer-reviewed journal focusing on evidence-based reports on the value or lack thereof of treatments intended to prevent or delay the onset of maladaptive correlates of aging in human beings. This journal is indexed on PubMed Central, MedLine,

\section{Dovepress}

CAS, Scopus and the Elsevier Bibliographic databases. The manuscript management system is completely online and includes a very quick and fair peer-review system, which is all easy to use. Visit http://www.dovepress. com/testimonials.php to read real quotes from published authors. 